\title{
PREDICTING THE PEAK SEISMIC RESPONSE OF A RETROFITTED NINE-STOREY STEEL REINFORCED CONCRETE BUILDING WITH STEEL DAMPER COLUMNS
}

\author{
KENJI FUJII ${ }^{1}$, HIROKI SUGIYAMA ${ }^{1} \&$ KAZUAKI MIYAGAWA ${ }^{2}$ \\ ${ }^{1}$ Chiba Institute of Technology, Japan \\ ${ }^{2}$ JFE Civil Engineering and Construction Corp., Japan
}

\begin{abstract}
A steel damper column using low-yield strength steel is an attractive choice for the seismic retrofitting of existing buildings because it does not introduce architectural problems, unlike braces and walls. In a seismic retrofit design using a steel damper column, the design of the connection joint between the damper column and the existing concrete member is very important. The designer needs to evaluate the maximum shear force and moment of the joint, in addition to the peak storey drift and member forces. In this study, the nonlinear peak response of a retrofitted nine-storey steel reinforced concrete building with steel damper columns was analytically investigated. A steel damper column was added on the side of the exterior frame by connection joint, using mortar, anchors, and studs. The peak response was predicted using nonlinear static (pushover) analysis, the peak storey drift, and the maximum moment and shear force at the connection joint, and the results were compared with the results obtained by nonlinear time-history analysis. Thus, it was revealed that the predicted peak storey drift, the maximum shear force, and moment at the connection joint are in good agreement with the time-history analysis results. The largest shear force of the anchor in the connection joint was also evaluated and compared with the time-history analysis results.
\end{abstract}

Keywords: seismic retrofit, existing steel reinforced concrete building, steel damper column, equivalent linearization technique, pushover analysis.

\section{INTRODUCTION}

The seismic retrofitting of existing buildings is important in most seismically active regions. In Japan, the seismic evaluation and retrofitting of existing reinforced concrete (RC) and steel reinforced concrete (SRC) buildings, and particularly that of public buildings including school buildings and government offices, has accelerated since the 1995 Hyogo-Ken Nanbu Earthquake. Although, in Japan, the seismic evaluation and retrofitting of school buildings have almost been completed, there still exist many condominiums and office buildings that are designed in accordance with the old seismic design code.

In recent years, many studies have been conducted on passive control systems for the seismic retrofitting of existing RC buildings [1]-[3] and the seismic design of new RC buildings [4]. A popular system is the buckling-restrained brace (BRB) system, which uses low-yield-strength steel. BRBs are undoubtedly effective in the seismic retrofitting of RC buildings because the structural system is clear; that is, the deformation of braces equals the shear deformation of the existing RC frame. However, the application of BRBs to the seismic retrofitting of existing buildings may introduce architectural problems. For example, in the case of the seismic retrofit of a condominium, installing BRBs in front of a balcony may obstruct the view from the living space window. Therefore, the use of a damper column with a shear panel [5] may be an attractive choice for the seismic retrofitting of existing condominiums and office buildings. In the damper column, shown in Fig. 1(a), low-yieldstrength steel was used for the shear panel to absorb the hysteresis energy. One possible scheme for the seismic retrofitting of a concrete office building with a steel damper column involves a direct connection to the side of exterior frame [6], as shown in Fig. 1(b). The 
details of the additional steel damper column connection to the existing concrete structure are shown in Fig. 2. An additional steel damper column is connected to an existing concrete structure through the joint using mortar, anchors and studs. Another possible scheme for a condominium with a balcony involves adding a new steel frame to the side of the balcony, as has been demonstrated by a previous study [3].

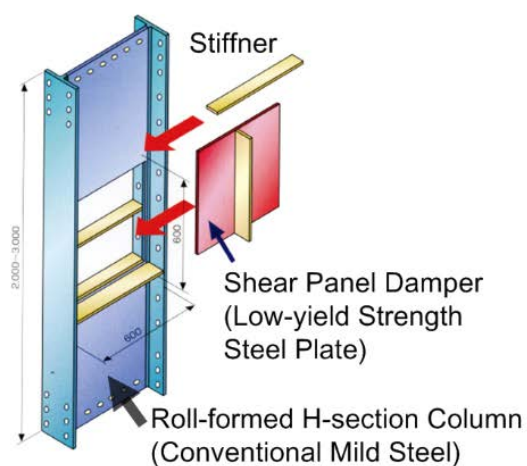

(a) Steel Damper Column

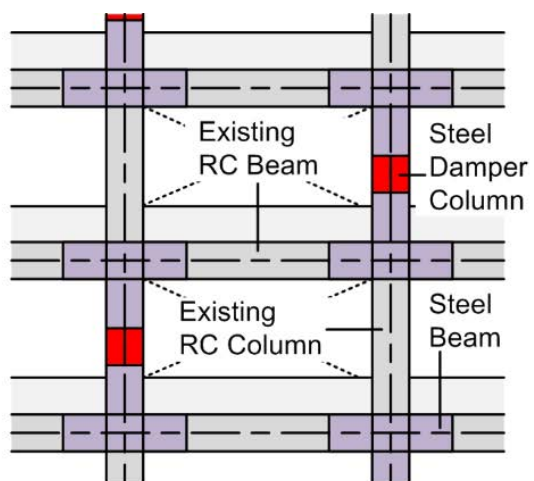

(b) Seismic Retrofit using Steel Damper Column

Figure 1: The seismic retrofit of an existing concrete office building using steel damper columns.

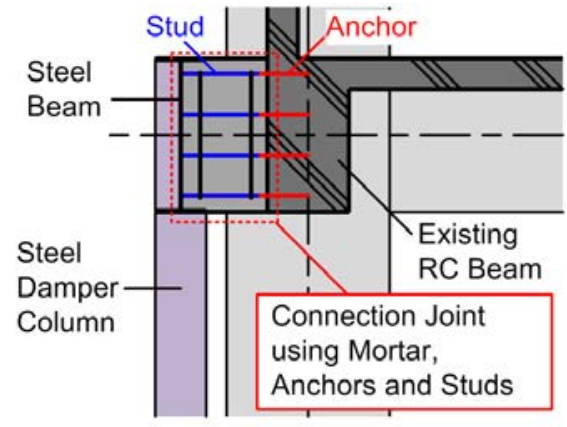

(a) Section

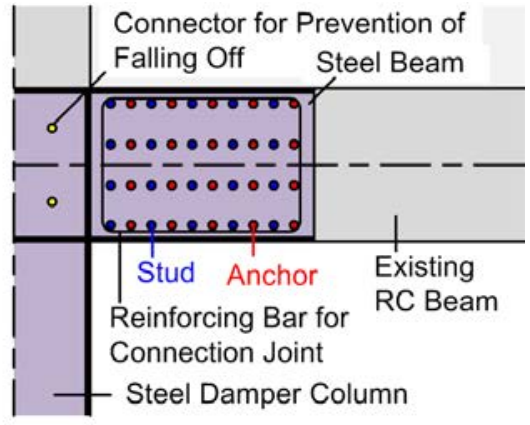

(b) Elevation

Figure 2: Detail of the connection of an additional steel damper column to an existing RC structure.

In seismic retrofit design using a steel damper column, the design of the connection joint between the damper column and the existing concrete member is very important. The designer needs to evaluate the maximum shear force and moment of the joint, in addition to the peak storey drift and member forces. In this study, the nonlinear peak response of a retrofitted nine-storey SRC building with steel damper columns was analytically investigated. The peak response of the retrofitted building was predicted through a previously proposed simplified procedure [3]. The predicted peak storey drift, maximum shear force and moment of the connection joint were compared with the time-history analysis results. 


\section{OUTLINE OF A SIMPLIFIED PROCEDURE}

The authors have proposed a simplified procedure to predict the peak response of retrofitted buildings using steel damper columns with consideration to the strain hardening effect [3]. In the abovementioned simplified procedure, the strain hardening effect is considered by using two models; namely, the lower-bound (LB) model and the upper bound model. In the LB model, the yielding strength of the damper panel is assumed to be the LB yielding strength $Q_{y D L}$, which corresponds to the initial yielding strength before the strain hardening. In the UB model, the yielding strength of the damper panel is assumed to be the UB yielding strength $Q_{y D U}$, which corresponds to the yielding strength after an appreciable amount of cyclic loading. The predicted peak response of each component is determined from the envelope of the prediction results obtained by the LB and UB models. The simplified procedure is outlined as follows:

- Step 1: Construct two nonlinear frame structure models, namely the LB model and the UB model.

- Step 2: Carry out pushover analysis of the LB model. Then determine the following properties of the equivalent single-degree-of-freedom (SDOF) model based on the pushover analysis results: (a) the relationship between the equivalent acceleration $A_{1}{ }^{*}$ and the equivalent displacement $D_{1}{ }^{*}$ (capacity curve); (b) the relationship between the equivalent damping $h_{1 e q}$ and $D_{1}{ }^{*}$.

- Step 3: Predict the peak equivalent displacement $D_{1}{ }^{*} \max$ employing the equivalent linearization [7].

- Step 4: From the results obtained in STEPS 2 and 3, obtain the peak response for each component (e.g., the peak storey drift, peak shear deformation and force of the damper panel) by referring to the pushover analysis result corresponding to $D_{1}{ }^{*}$ max. The maximum response occurring until the equivalent displacement reaches $D_{1}{ }^{*}$ max is the predicted peak response of each component obtained from the LB model.

- Step 5: Repeat STEPS 2 to 4 to obtain the peak response of the UB model.

- Step 6: Determine the predicted peak response of each component from the LB and UB models' envelope of predicted peak responses.

The details of the simplified procedure have been discussed in a previous paper [3].

\section{BUILDING AND GROUND MOTION DATA}

\subsection{Building data}

This study investigated a nine-storey steel reinforced concrete office building model designed in accordance with the pre-1981 seismic code of Japan. Fig. 3 shows the building model considered in this study. Because the plan of this building is symmetric, only two frames (frame Y1 and Y2) were analysed. Additional shear reinforcement through carbon fibre was assumed to have been properly provided to the existing members shown in frame Y1 to prevent shear failure. The model without an additional steel damper column is termed as Model-O, and had a base shear coefficient of 0.224 . Two retrofitted building models, namely, Model-D100 and Model-D225, were considered in this study. The two models were different with respect to the steel damper column. The parameters of the steel damper column for each model are presented in Table 1. The thickness of the damper panel is denoted as $t_{d}$, the assumed initial nominal yield stress is denoted as $\sigma_{y L}$, the assumed nominal yield stress after appreciable cyclic loading, $\sigma_{y U}$, the initial shear yield strength is denoted as $Q_{y D L}$, and the shear yield strength after an appreciable amount of cyclic loading is denoted as $Q_{y D U}$. In both 
retrofitted building models, a steel damper column was added in each storey shown in Fig. 3(b). The ratio of $Q_{y D L}$ to the total weight of the structure was 0.033 for Model-D100, and 0.054 for Model-D225.

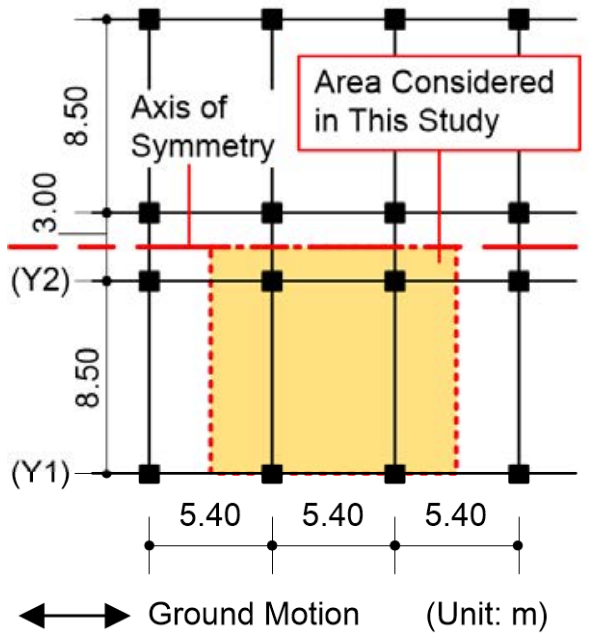

(a) Plan

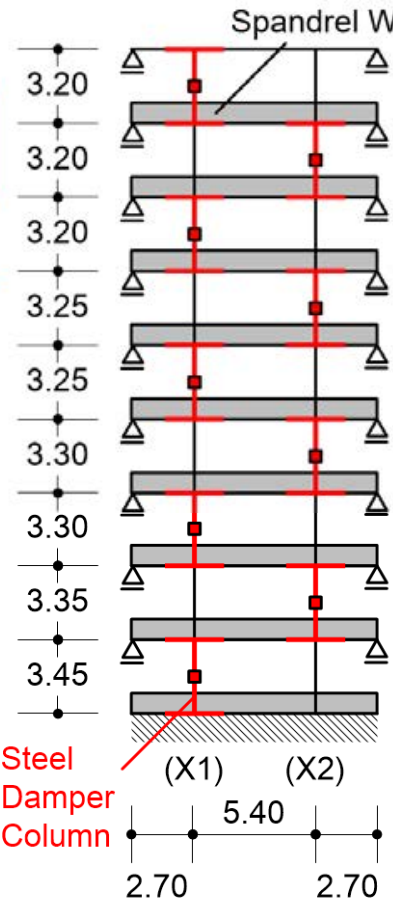

Frame $\mathrm{Y} 1$

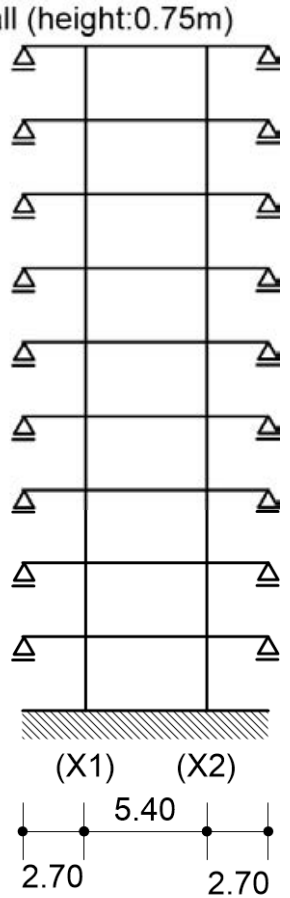

Frame Y2

(b) Elevation

Figure 3: Building model.

Table 1: Steel damper column parameters for each model.

\begin{tabular}{|l|c|c|c|c|c|c|}
\hline \multirow{2}{*}{ Model } & \multirow{2}{*}{ H-Section Column } & \multicolumn{5}{|c|}{ Damper Panel } \\
\cline { 3 - 7 } & & $\begin{array}{c}t_{d} \\
(\mathrm{~mm})\end{array}$ & $\begin{array}{c}\sigma_{y L} \\
\left(\mathrm{~N} / \mathrm{mm}^{2}\right)\end{array}$ & $\begin{array}{c}\sigma_{y U} \\
\left(\mathrm{~N} / \mathrm{mm}^{2}\right)\end{array}$ & $\begin{array}{c}Q_{y D L} \\
(\mathrm{kN})\end{array}$ & $\begin{array}{c}Q_{y D U} \\
(\mathrm{kN})\end{array}$ \\
\hline Model-D100 & \multirow{2}{*}{$\mathrm{H}-750 \times 250 \times 14 \times 28$} & 9.0 & 100 & 200 & 382 & 764 \\
\cline { 1 - 6 } & & 6.0 & 225 & 300 & 618 & 824 \\
\hline
\end{tabular}

Fig. 4 shows the detail of the connection joint. In this study, the size of the anchor is assumed as D16 (shear strength $q_{a}=64 \mathrm{kN}$ ). The number of anchors was determined such that the shear force of the outermost anchor $q$ did not exceed the shear strength $q_{a}$, by considering the design moment of the connection joint, $M_{J D}$, as follows:

$$
q=\frac{\sqrt{L_{X}{ }^{2}+L_{Y}^{2}}}{r_{J}^{2}} \frac{M_{J D}}{N_{a}} \leq q_{a}=64 \mathrm{kN} .
$$



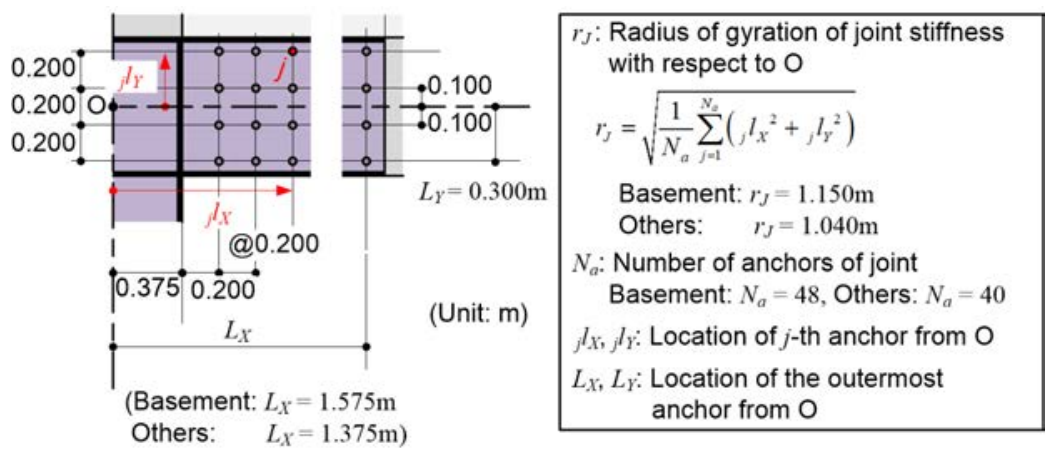

Figure 4: Detail of connection joint.

In this study, the same connection joints were assumed for both models. The design moment of joint $M_{J D}$ was assumed $1990 \mathrm{kNm}(=0.7 \times 824 \mathrm{kN} \times 3.45 \mathrm{~m})$ for the basement, and as $1380 \mathrm{kNm}(=0.5 \times 824 \mathrm{kN} \times 3.35 \mathrm{~m})$ elsewhere.

\subsection{Modelling of building structures}

Fig. 5 shows the numerical modelling of the building structures, while Figs 6 and 7 show the force-deformation relationship for each member (envelopes in Fig. 6; hysteresis rules in Fig. 7).

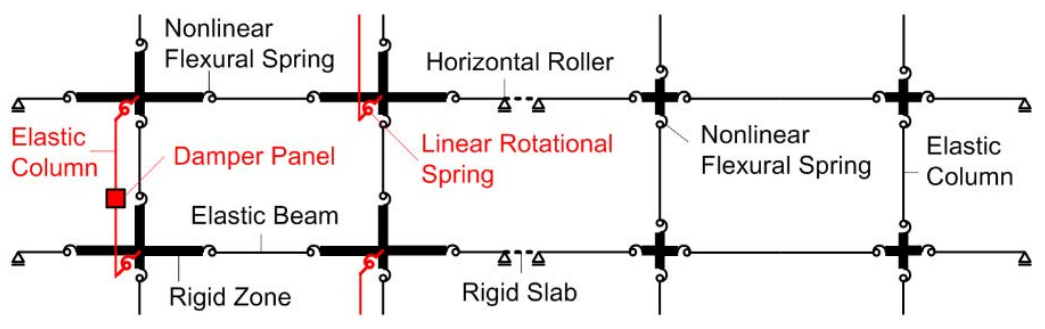

Frame $\mathrm{Y} 1$

Frame $\mathrm{Y} 2$

Figure 5: Numerical modelling of building structure.

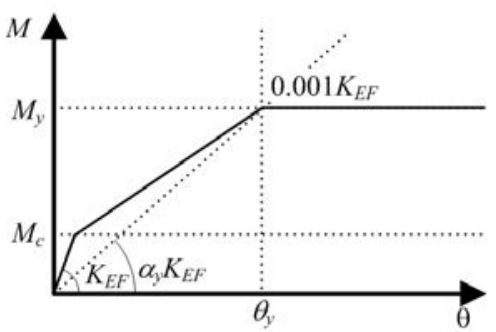

(a) Nonlinear Flexural Spring (Existing SRC Columns and Beams)

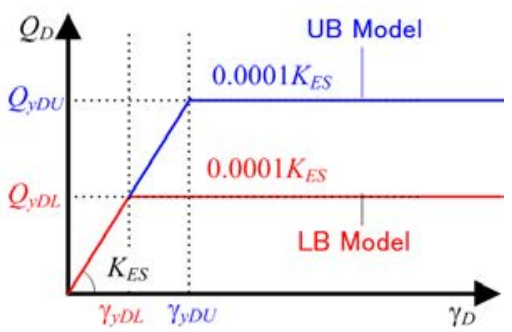

(b) Shear (Damper Panel)

Figure 6: Envelope of force-deformation relationship. 


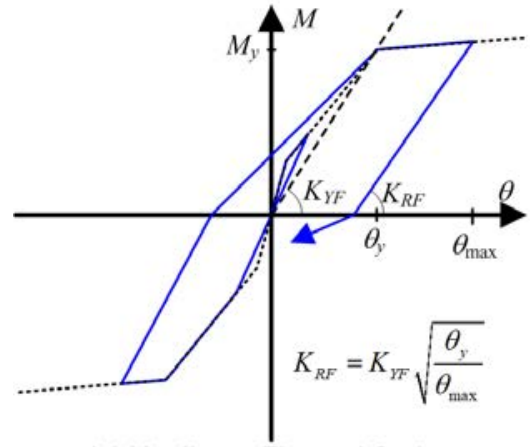

(a) Nonlinear Flexural Spring

(Existing SRC Column and Beam)

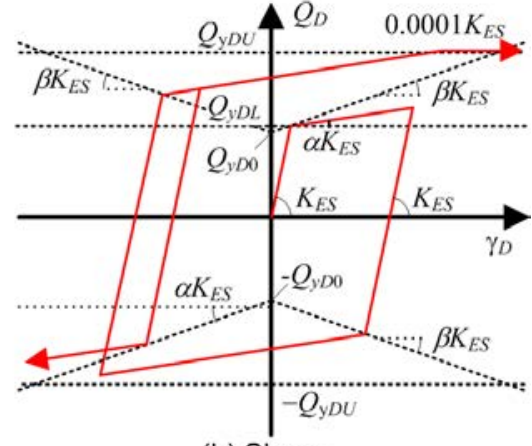

(b) Shear

(Damper Panel)

Figure 7: Hysteresis rule for each member.

In this study, the building was modelled as a plane frame model. Frames Y1 and Y2 were connected through the rigid slab. All existing beams and columns were modelled as an elastic beam/column with a nonlinear flexural spring at each end, except beam with the horizontal roller. The flexural and shear deformations were considered in the elastic beam, while the flexural, shear and axial deformations are considered in the elastic column. The rigid zone was considered in the existing members, and particularly in the case of Models D100 and D225. The rigid zone length of all beams in Frame Y1 was assumed as the same length as $L_{X}$ shown in Fig. 4, with consideration to the additional steel beam. The joint of the additional steel damper column connection to the existing frame was modelled as a linear rotational spring, and its stiffness was calculated as:

$$
K_{J}=N_{a} k_{a} r_{J}^{2} .
$$

Here, $k_{a}$ is the elastic shear stiffness of the connection joint per number of anchors and was assumed $250 \mathrm{MN} / \mathrm{m}$, based on the experimental results in [6]. The damper column was modelled as an elastic column with a damper panel in the middle. The flexural behaviour of damper panel was assumed to be linear elastic, and the shear behaviour was assumed to be nonlinear. The height of damper panel is assumed $0.75 \mathrm{~m}$.

For all members, the force-deformation relationship envelopes were assumed to be symmetric in the positive and negative loading directions. For the existing SRC members, the envelope was assumed to be the tri-linear curve shown in Fig. 6(a). At yielding, the ratio of secant stiffness degradation to the initial stiffness $\alpha_{y}$ was assumed 0.10 for the beams with spandrel wall based on Takahashi et al. [8], For the other beams, $\alpha_{y}$ was assumed as 0.25 . To determine the tri-linear curve for the columns, the rotational angle at yielding $\theta_{y}$ was assumed in the range between $1 / 250$ and $1 / 150$, depending on each column's clear height to depth ratio $H_{0} / D$. The bi-linear envelopes shown in Fig. 6(b) were assumed for the shear behaviour of the damper columns (in the LB/UB models). The Muto hysteresis model [9] with one modification was used to model the nonlinear flexural spring, as shown in Fig. 7(a). The hysteresis model proposed by Ono and Kaneko [10] was used to model the shear behaviour of the damper columns with consideration to the strain-hardening behaviour for the nonlinear time-history analysis, as shown in Fig. 7(b). Parameter $\alpha$ was assumed as 0.005 for ModelD100 and as 0.022 for Model-D225, while parameter $\beta$ is assumed 0.013 for both models. 
Note that, for the nonlinear time-history analysis, the initial yield strength of the damper panel shown in Fig. 7(b) was assumed to be $Q_{y D L}$ while the UB yield strength was assumed to be $Q_{y D U}$.

The damping matrix was assumed to be proportional to the instant stiffness matrix without a damper column. The damping ratio of the elastic first mode of the model without a damper column was assumed to as 0.05 .

\subsection{Ground motion data}

Fig. 8 shows the elastic response spectra of the artificial ground motions used in this study. Twelve artificial ground motions generated in a previous study (Art-L00 to 11 in [3]) were used to conduct the nonlinear time-history analysis. The target elastic spectrum was the design spectrum determined from the Building Standard Law of Japan [11] with consideration to the type-1 soil condition. The horizontal major component of Sendai Government Office building \#2, which was recorded during the 2011 earthquake off the Pacific coast of Tohoku [12], was used as the source of phase angle of the artificial ground motions.

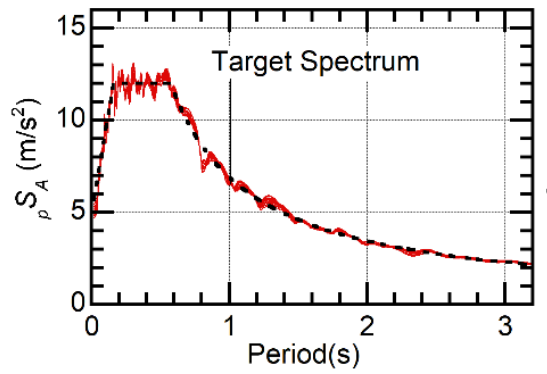

(a) Pseudo Acceleration Spectrum

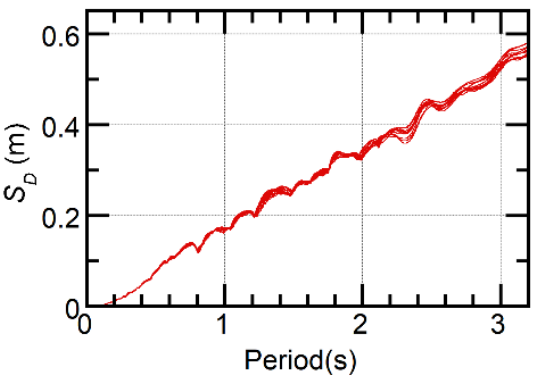

(b) Displacement Spectrum

Figure 8: Elastic response spectra of artificial ground motions

\section{ANALYSIS RESULTS}

\subsection{Prediction of peak response in simplified procedure}

Fig. 9 shows the prediction of the peak equivalent displacement $D_{1}{ }^{*}$ max for all models. As expected, the comparison results revealed that the predicted peak response of the model building was effectively reduced with the addition of dampers. The predicted $D_{1}{ }^{*}$ max for Model-O was $0.220 \mathrm{~m}$, while the values for the models with dampers were within the range of $0.144-0.151 \mathrm{~m}$.

4.2 Comparison results obtained from the nonlinear time-history analysis and simplified procedure

\subsubsection{Peak storey drift}

Fig. 10 shows the comparisons of the peak storey drift $R_{\max }$, which were obtained from the nonlinear time-history analysis and simplified procedure, respectively. As can be seen, the predicted $R_{\max }$ is in good agreement with the time-history analysis results. Fig. 10(b) and (c) 


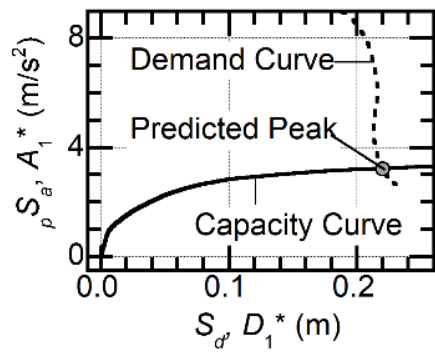

(a) Model-O

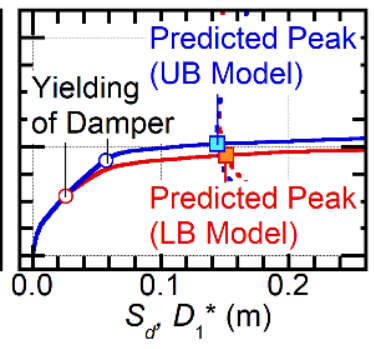

(b) Model-D100

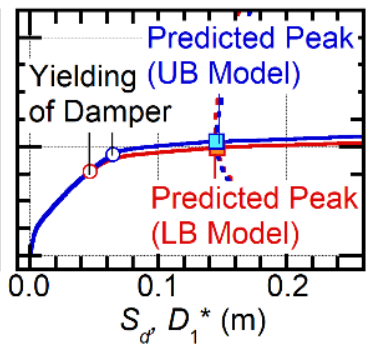

(c) Model-D225

Figure 9: Prediction of the peak equivalent displacement.

also show that, for the models with dampers, the predicted (envelope) $R_{\max }$ for the part of the structure between the fifth to seventh stories was determined from the result obtained by the LB model. Moreover, the predicted (envelope) $R_{\max }$ for the other part of the structure was determined from the result obtained from the UB model. This implies that it was reasonable to use of two models (LB and UB models) to predict the peak response.

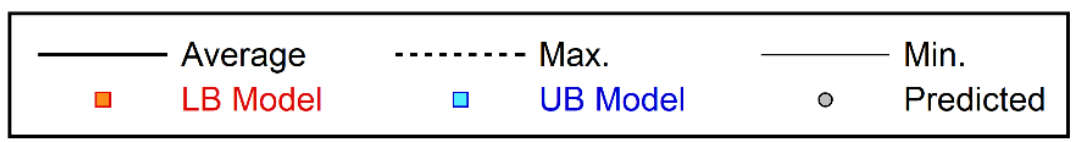

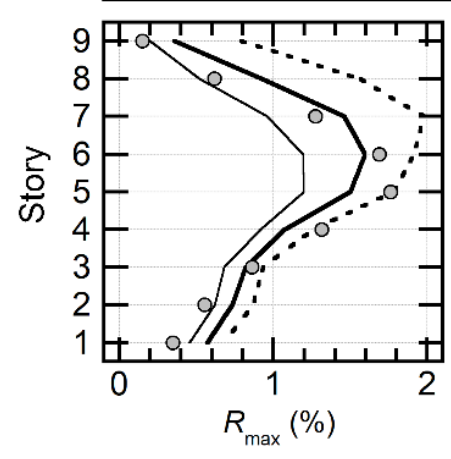

(a) Model-O

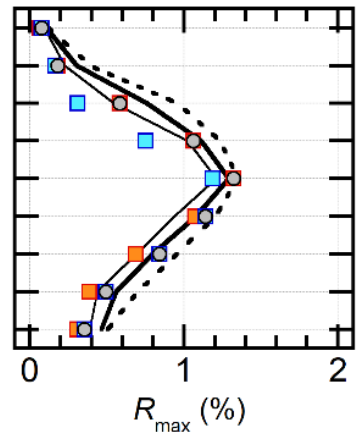

(b) Model-D100

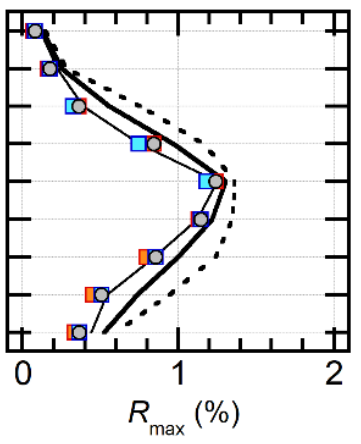

(c) Model-D225

Figure 10: Comparisons of peak storey drift.

\subsubsection{Maximum shear force and moment of connection joint}

Fig. 11 shows the comparison results for the maximum shear force at the connection joint $Q_{J \max }$, which were obtained from the nonlinear time-history analysis and simplified procedure. In this study, $Q_{J \max }$ was obtained as the maximum shear force of each steel damper column. As shown in Fig. 11(a), the $Q_{J \max }$ prediction was conservative for Model-D100, because the results obtained from the time-history analysis lie between the results obtained from the LB and UB models, except for the eighth and ninth floor of column X1. However, for ModelD225 shown in Fig. 11(b), the predicted $Q_{J \max }$ agrees with the nonlinear time-history analysis results, with the exception of the upper floors. 


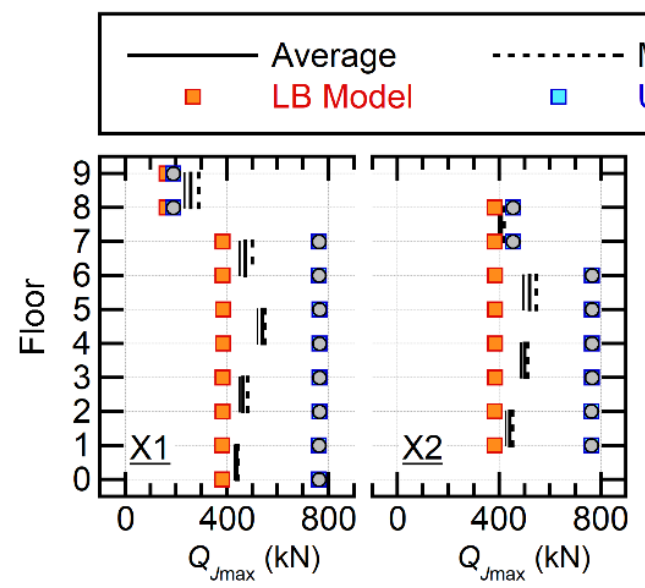

(a) Model-D100

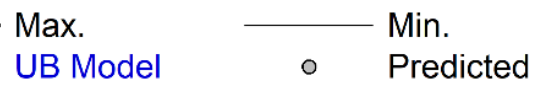

Max.

UB Model $\quad \circ \quad$ Predicted

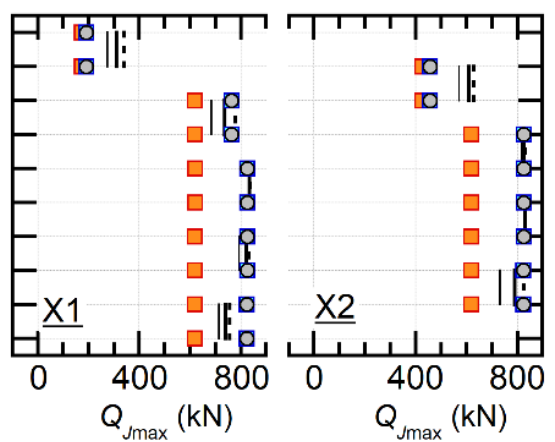

(b) Model-D225

Figure 11: Comparisons of maximum shear force at connection joint.

Fig. 12 shows the comparison results for the maximum moment at the connection joint $M_{J_{\max }}$, which were obtained by the nonlinear time-history analysis and simplified procedure. As shown in Fig. 12, the $M_{J \max }$ prediction is conservative for Model-D100 (Fig. 12(a)). However, for Model-D225 shown in Fig. 12(b), the predicted $M_{J \max }$ agrees with the nonlinear time-history analysis results.

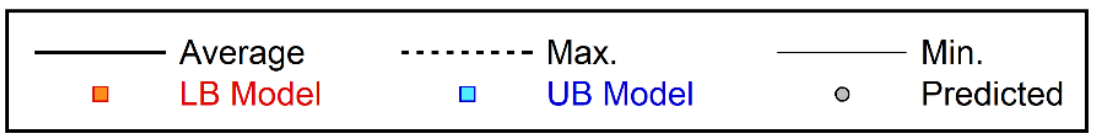

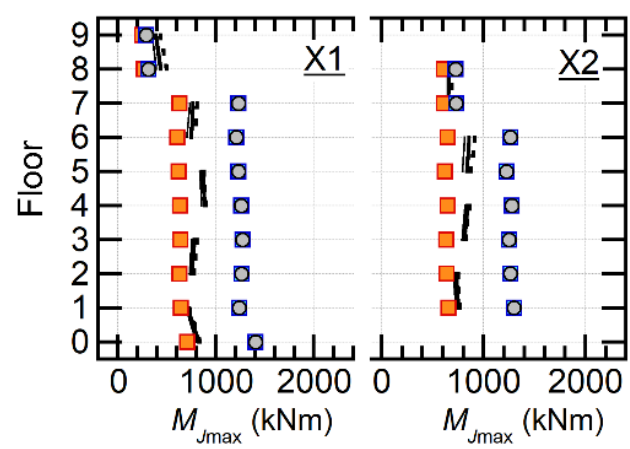

(a) Model-D100

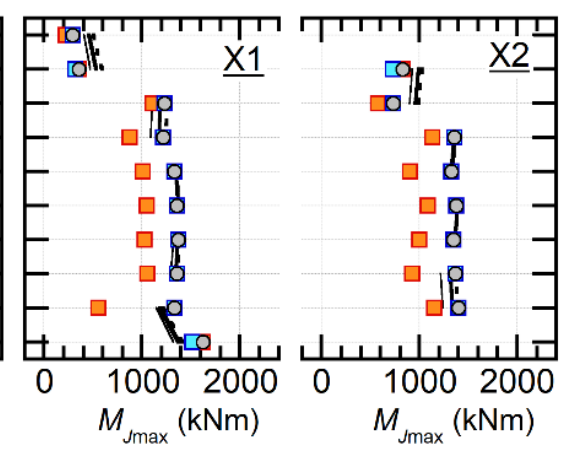

(b) Model-D225

Figure 12: Comparisons of maximum moment at connection joint.

For most of the connection joint, the $Q_{J \max }$ and $M_{J \max }$ were predicted from the results of the UB model. However, the $M_{J \max }$ at the basement of column X1, top of column X2 of the eighth storey, and bottom of column X1 of the ninth storey were predicted from the result obtained by the LB model. 
4.2.3 Largest shear force of anchor in connection joint

Fig. 13 shows the comparison results of obtained by the nonlinear time-history analysis and simplified procedure for the largest shear force of anchor in connection joint $q_{\max }$. In this figure, the shear strength of the D16 anchor $q_{a}(=64 \mathrm{kN})$ is also shown. Moreover, in this study, $q_{\max }$ is calculated from $Q_{J \max }$ and $M_{J \max }$, as follows:

$$
q_{\max }=\frac{1}{N_{a}} \sqrt{\left(Q_{J \max }+\frac{L_{Y}}{r_{J}^{2}} M_{J \max }\right)^{2}+\left(\frac{L_{X}}{r_{J}^{2}} M_{J \max }\right)^{2}} .
$$

As shown in Fig. 13(a), the $q_{\max }$ prediction is conservative for Model-D100, except for the eighth and ninth floor of column X1. However, for Model-D225 shown in Fig. 13(b), the predicted $q_{\max }$ agrees with the nonlinear time-history analysis results, with exception of the upper floors. This figure also shows that, in all connection joints, $q_{\max }$ was smaller than the shear strength. Therefore, it was expected that all steel damper columns would be properly connected to the existing structure by the joint shown in Fig. 4.

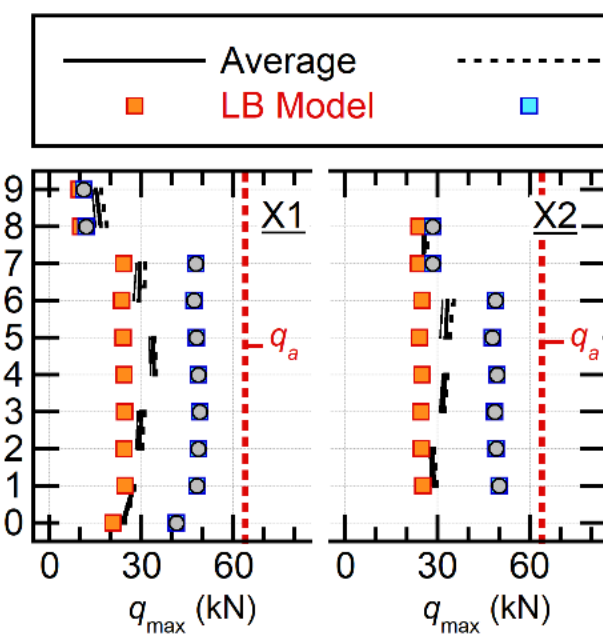

(a) Model-D100

\section{Max. \\ UB Model \\ Min. \\ Predicted}

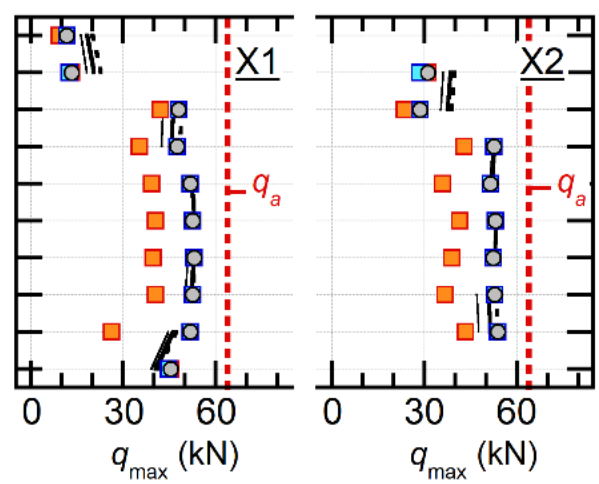

(b) Model-D225

Figure 13: Comparisons of largest shear force for anchor in connection joint.

\section{CONCLUSIONS}

In this study, the nonlinear peak response of a retrofitted nine-storey SRC building with steel damper columns was analytically investigated. The peak response of the retrofitted building was predicted through a previously proposed the simplified procedure [3], and the obtained results were compared with the results obtained by nonlinear time-history analysis.

The comparison results revealed that the simplified procedure could satisfactorily estimate the peak response. The largest shear force of the anchor in the connection joint was also properly estimated through the simplified procedure.

\section{ACKNOWLEDGEMENT}

We thank Edanz Group (www.edanzediting.com/ac) for editing a draft of this manuscript. 


\section{REFERENCES}

[1] Ishii, T., Mukai, T., Kitamura, H., Shimizu, T., Fujisawa, K. \& Ishida, Y., Seismic retrofit for existing $\mathrm{R} / \mathrm{C}$ building using energy dissipative braces. Proceedings of the 13th World Conference on Earthquake Engineering, paper no. 1209, 2004.

[2] Mazza, F. \& Vulcano, A., Displacement-based design procedure of damped braces for the seismic retrofitting of RC framed buildings. Bulletin of Earthquake Engineering, 13, pp. 2121-2143, 2015.

[3] Fujii, K. \& Miyagawa, K., Nonlinear seismic response of a seven-storey steel reinforced concrete condominium retrofitted with low-yield-strength-steel damper columns. Proceedings of the 16th European Conference on Earthquake Engineering, paper no. 10736, 2018.

[4] Izumi, M., Chiba, O., Takahashi, K. \& Iizuka, S., Earthquake resistant performance of reinforced concrete frame with energy dissipation devices. Proceedings of the 13th World Conference on Earthquake Engineering, paper no. 2498, 2004.

[5] Katayama, T., Ito, S., Kamura, H., Ueki, T. \& Okamoto, H., Experimental study on hysteretic damper with low yield strength steel under dynamic loading. Proceedings of the 12th World Conference on Earthquake Engineering, paper no. 1020, 2000.

[6] Kitamura, K., Fujinaga, T., Miyagawa, K., Kitamura, W. \& Sun, Y., Study on cyclic behavior of indirect connection between existing $\mathrm{R} / \mathrm{C}$ beam and retrofitting steel frame. Proceedings of the 10th Symposium on Research and Application of Hybrid and Composite Structures, paper no. 60, 2013. (In Japanese.)

[7] Otani, S., New seismic design provision in Japan. Proceedings of the Second USJapan Workshop on Performance-Based Earthquake Engineering Methodology for Reinforced Concrete Structures, PEER Report 2000/10, pp. 3-14, 2000.

[8] Takahashi, S., Ueda, H., Sumi, A., Ichinose, T., Sobue, M. \& Tanaka, H., A flexuraldesign model of reinforced concrete members with spandrel and wing wall. Journal of Structural and Construction Engineering (Transaction of AIJ), 74(641), pp.13211326, 2009. (In Japanese.)

[9] Muto, K., Hisada, T., Tsugawa, T. \& Bessho, S., Earthquake resistant design of a 20 storey reinforced concrete buildings. Proceedings of the Fifth World Conference on Earthquake Engineering, pp. 1960-1969, 1974.

[10] Ono, Y. \& Kaneko, H., Constitutive rules of the steel damper and source code for the analysis program. Passive control symposium 2001, Structural Engineering Research Center, Tokyo Institute of Technology, pp. 163-170, 2001. (In Japanese.)

[11] BCJ, The Building Standard Law of Japan on CD-ROM, The Building Center of Japan, 2016.

[12] Kashima, T., Koyama S. \& Okawa I., Strong Motion Records in Buildings from the 2011 off the Pacific Coast of Tohoku Earthquake, Building Research Institute, 2012. (In Japanese.) 